\title{
CARACTERIZAÇÃO HIDROGEOLÓGICA E HIDROQUÍMICA DO SISTEMA AQUÍFERO BAURU NO MUNICÍPIO DE BASTOS (SP)
}

\author{
Tatiana Tavares $^{(1)}$, Cláudia Varnier ${ }^{(2)}$, Renato Bevilacqua ${ }^{(1)}$, Nádia Correa ${ }^{(1)}$, Luiz Gustavo \\ Faccini $^{(1)}$, Ana Maciel de Carvalho ${ }^{(1)}$, Jose Luiz Albuquerque Filho ${ }^{(1)}$, Mara Akie Iritani ${ }^{(2)}$, Geraldo \\ Oda $^{(2)}$, Luciana Martin Rodrigues Ferreira ${ }^{(2)}$, Emílio Prandi ${ }^{(3)}$, Suraya Modaelli ${ }^{(3)}$
}

\section{RESUMO}

A avicultura, principal atividade econômica do município de Bastos, é responsável pela produção de grandes volumes de resíduos que, dispostos de forma inadequada, podem constituir em fonte potencial de contaminação das águas subterrâneas do Sistema Aquífero Bauru (SAB), principal fonte de abastecimento público no local.

Nesse contexto, o IPT está desenvolvendo um projeto com outras instituições no município, buscando definir alterações de qualidade no SAB e definir as fontes antrópicas responsáveis. Uma parte do trabalho está apresentada nesse artigo que objetiva apresentar a caracterização hidrogeológica e hidroquímica do SAB no município de Bastos. Para tanto, foi feita uma revisão bibliográfica de estudos no local e levantamento de mapas temáticos, levantamento geofísico, cadastramento de poços outorgados, coleta de amostras de água subterrânea para análises físicoquímicas e, consolidação e interpretação dos dados.

Como resultado, caracterizou-se a geometria do SAB no município, bem como suas características hidrodinâmicas. E através da hidroquímica, classificou-se a composição natural de suas águas, bem como se identificou um grupo de águas com evidente alteração de qualidade.

\section{ABSTRACT}

The poultry industry, the main economic activity of the Bastos municipality is responsible for the production of large volumes of waste, which disposed improperly, could constitute a possible source of groundwater contamination of the Bauru Aquifer System (SAB), the main source of regional public water supply.

\footnotetext{
${ }^{1}$ Instituto de Pesquisas Técnológicas - IPT /LABGEO/CTGeo. Av. Prof. Almeida Prado, 532 - Butantã, São Paulo - SP, 05508-901, tel: (11) 37674936, e-mail: ttavares@ipt.br; ${ }^{2}$ Instituto Geológico / Secretaria do Meio Ambiente - IG/SMA. R. Joaquim Távora, 822 - Vila Mariana, São Paulo SP, 04015-011, tel: (11) 5073-5511, e-mail: clvarnier@hotmail.com; ${ }^{3}$ Departamento de Águas e Energia Eletrica do Estado de Sao Paulo - DAEE. Rua Benedito Mendes Faria, 40a, Vila Hipica, Marilia / SP, CEP 17520-520, tel: (14) 34171017, e-mail: suraya.modaelli@gmail.com.
} 
In this context, the IPT has been developing a project along with other institutions (IG) aiming both establish SAB's quality problems and determine the anthropic pollution sources associated. A first part of this work is presented in this article, to show the SAB's hydrogeological and hydrochemical characterization at Bastos municipality. The activities to achieve the goals were a bibliographic review of local studies, survey of thematic maps, geophysical survey, groundwater sampling for physicochemical and chemical analysis, and consolidation and interpretation of data.

As a result, the SAB's geometry in the city was characterized as well as its hydrodynamic characteristics. The natural composition of the groundwater was identified by the hydrochemistry data, as well as a different composition with quality alteration associated with anthropogenic sources.

PALAVRAS-CHAVE: Sistema Aquífero Bauru, Hidroquímica, Bastos.

\section{INTRODUÇÃO}

O nitrato é o contaminante inorgânico de maior ocorrência em aquíferos no mundo, dada à sua alta mobilidade e persistência. Estudos hidrogeológicos desenvolvidos pelo Instituto Geológico/SMA, Universidade de São Paulo e CETESB têm detectado esse contaminante extensivamente nos aquíferos paulistas (VARNIER, 2011). Essa situação tem preocupado administradores dos recursos hídricos em diversas esferas municipais e estaduais, dado ao crescente número de casos reportados nas áreas urbanas e rurais de diversas cidades do interior paulista.

Dentre as fontes potenciais de nitrato em áreas rurais citam-se as atividades agropecuárias, incluindo a aplicação de fertilizantes nitrogenados, criação de animais, bem como os sistemas de saneamento in situ (fossas sépticas e negras).

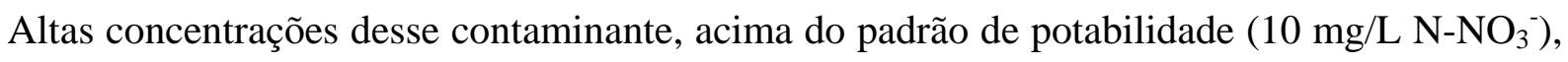
foram encontradas em vários poços tubulares e cacimbas situados nas áreas urbanas e rurais de vários municípios do Estado de São Paulo, abastecidos parcial ou totalmente pelas águas do Sistema Aquífero Bauru (SAB), considerado a maior unidade hidrogeológica em área exposta do Estado de São Paulo. Este sistema aquífero ocupa uma superfície de aproximadamente $96.000 \mathrm{~km}^{2}$, onde cerca de 240 municípios (59\%) das regiões centro-oeste do território paulista captam suas águas e, em 210 destes (87\%), o abastecimento é integralmente feito por água subterrânea (VARNIER, 2011).

Dentre os municípios abastecidos pelo SAB, destaca-se o de Bastos. Estudos efetuados por FREITAS (2015) mostram que ocorrem concentrações elevadas de nitrato (até 51,2 mg/L N- $\mathrm{NO}_{3}{ }^{-}$) em poços tubulares situados na área rural do referido município. A ocorrência desses valores 
estaria, possivelmente, associada às atividades das granjas que operam na região e, que futuramente, poderiam comprometer a qualidade da água dos poços de abastecimento público. Ainda segundo este autor, faz-se necessário um estudo mais detalhado para melhor caracterização dessas ocorrências.

Diante deste cenário, um estudo financiado pelo Fundo Estadual de Recursos Hídricos (FEHIDRO) está sendo desenvolvido para melhor caracterizar a contaminação de nitrato no Sistema Aquífero Bauru na área rural do município de Bastos, buscando identificar a(s) fonte(s) de contaminação a ele associada(s); e este artigo consolida a caracterização hidrogeológica e hidroquímica do SAB na área de estudo.

\section{OBJETIVO}

O objetivo principal deste artigo é caracterizar a hidrogeologia e hidroquímica do SAB no município de Bastos.

\section{3. ÁREA DE ESTUDO}

\subsection{Aspectos Gerais}

A área de estudo compreende a área rural do Município de Bastos, situado a $550 \mathrm{~km}$ da capital paulista. Este município, com uma área territorial de aproximadamente $172 \mathrm{~km}^{2}$, limita-se a norte com o município de Iacri, a sul com Rancharia, a leste com Tupã e a oeste, com Parapuã, UGRHIs 20 e 21 (Figura 1). O acesso ao local pode ser feito através das rodovias Castelo Branco (SP 280) até Botucatu, seguindo pela Marechal Rondon (SP 300) até Bauru e pela Comandante João Ribeiro de Barros (SP 294) até Bastos.

Segundo o censo demográfico de 2010, a população total de Bastos é de 20.446 habitantes, sendo que deste total, 17.609 (86\%) concentram-se na área urbana e 2.837 (14\%), na área rural (SEADE, 2013).

A principal atividade econômica no início da história do município foi a agricultura e criação do bicho da seda até os anos 50. A partir dessa data, gerou-se uma nova diversidade agrícola que incluiu o cultivo de amendoim, laranja, melancia, café, algodão, entre outros, e também as granjas de avicultura de postura (ENGFLORA, 2014). Hoje é considerado o maior produtor de ovos do Brasil, responsável pela produção de $60 \%$ do consumo de ovos do Estado, e $20 \%$ do consumo nacional, equivalente a 14,4 milhões de ovos/dia (BASTOS, 2012). 
Segundo levantamento realizado pela Secretaria da Agricultura do Estado de SP (CATI, 2009), a avicultura para ovos é a principal fonte de renda agrossivilpastoril no município (total de 10.611.266 cabeças), seguida pela codornicultura (346.000 cabeças) e pela piscicultura (116.305 cabeças). A suinocultura (16.272 cabeças), sericultura (16.272 cabeças) e bovinocultura (corte: 12.246; leite: 3.580 cabeças) são exercidas em menor proporção (CATI, 2009).

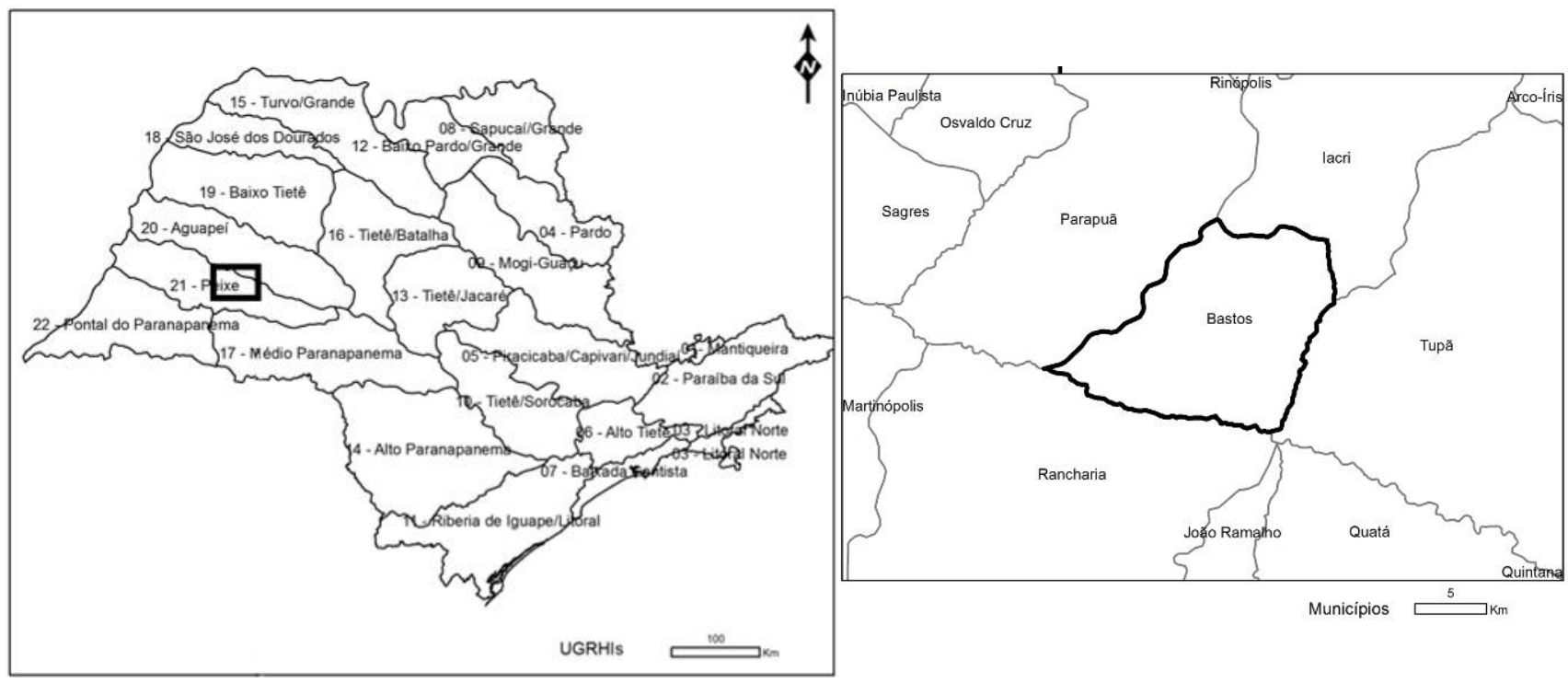

Figura 1 - Localização da área estudo.

Verifica-se que o uso e ocupação do solo rural no município de Bastos tem a predominância de pastagem (63,5\%), seguida por cultura temporária (21,3\%) constituída predominantemente por cana-de-açúcar e secundariamente pelo milho, amendoim e outros; e cultura perene (6,05\%) composta principalmente por pomares (tangerina, lichia, manga), amora, gramíneas de pastagem, etc. Quanto à vegetação natural, vegetação de brejo e reflorestamento, somados cobrem 9,10\% da área do território (CATI, 2009).

O Serviço de Saneamento Básico é de responsabilidade da Companhia de Saneamento Básico do Estado de São Paulo - SABESP. A cidade possui coleta e tratamento de esgoto que atinge 100\% do perímetro urbano do município, com 4.000 ligações de esgoto existentes (BASTOS, 2014).

Parte da captação de água para abastecimento público é proveniente de poços tubulares que captam água do Sistema Aquífero Bauru.

\subsection{Geologia}

Segundo o mapa geológico do Estado de São Paulo (DAEE/UNESP, 1980), o subsolo do município de Bastos é composto por rochas sedimentares da Formação Adamantina do Grupo 
Bauru, sobrepostas às rochas da Formação Araçatuba, que têm como substrato as rochas basálticas da Formação Serra Geral na região.

Segundo Prandi (2010), a Formação Adamantina é a de mais ampla distribuição em área nas bacias dos rios Aguapeí e Peixe, dentre as formações do Grupo Bauru. Estende-se pela superfície de quase toda a área, estando sobreposta apenas pela Formação Marília, na porção leste dessas bacias. Sua máxima espessura ocorre na região central, chegando a ter mais de 100 metros de espessura no município de Iacri. Nos vales dos principais rios e no extremo oeste dessas bacias, esta formação foi suprimida pela erosão, onde afloram os sedimentos da Formação Araçatuba, como observado por Prandi (2010) no Vale do Rio do Peixe.

A Formação Adamantina é composta por bancos de arenitos róseos a castanhos, de espessura variando entre 2 e 20 m, de granulação fina a muito fina, com estratificação cruzada, intercalados por bancos de lamitos, siltitos e arenitos lamíticos de cor castanho avermelhada a cinza castanho, maciços ou com acamamento plano-paralelo, com marcas de onda e microestratificação cruzada (SOARES et al.,1980).

Segundo CETEC (1997), a Formação Adamantina apresenta variação faciológica no município de Bastos (Figura 2). A unidade Ka1 é caracteristicamente mais arenosa, composta por arenitos finos a muito finos, siltitos arenosos, arenitos argilosos, e subordinadamente arenitos com granulometria média, quartzosos, localmente arcoseanos. Já a unidade Ka4 é mais enriquecida em sedimentos finos e presença moderada de cimentação carbonática, composta por arenitos finos a muito finos, quartzosos, com frequentes intercalações de argilitos e siltitos, formando bancos espessos, e localmente, arenitos com pelotas de argila. A presença da Formação Marília (Km) que normalmente possui maior cimentação carbonática ocorre no noroeste do município, como indicado no mapa da UNESP/DAEE (1980). E uma pequena porção aflorante da Formação Serra Geral (JKsg) ocorre no extremo oeste do município (Figura 2).

\subsection{Hidrogeologia}

O Sistema Aquífero Bauru ocupa aproximadamente a metade oeste do Estado de São Paulo, com área de $96.880 \mathrm{~km}^{2}$ e foi dividido em duas unidades hidroestratigráficas (DAEE, 1979): Bauru Médio/Superior (Grupo Bauru) e Bauru Inferior/Caiuá (Grupo Caiuá).

Na região de estudo ocorre apenas o primeiro, caracterizado como uma unidade hidrogeológica contínua, livre a semiconfinada, de extensão regional, constituído de arenitos finos e mal selecionados na base, de arenitos argilosos e calcíferos no topo. Apresenta vazão média de produção dos poços igual a $8 \mathrm{~m}^{3} / \mathrm{h}$ (DAEE, 2005). Segundo Rocha et al. (1979), os valores médios de transmissividade predominantes da 
porção inferior do Bauru estão entre $30 \mathrm{~m}^{2} / \mathrm{h}$ e $50 \mathrm{~m}^{2} / \mathrm{h}$ e correspondem ao domínio de ocorrência da Formação Adamantina.

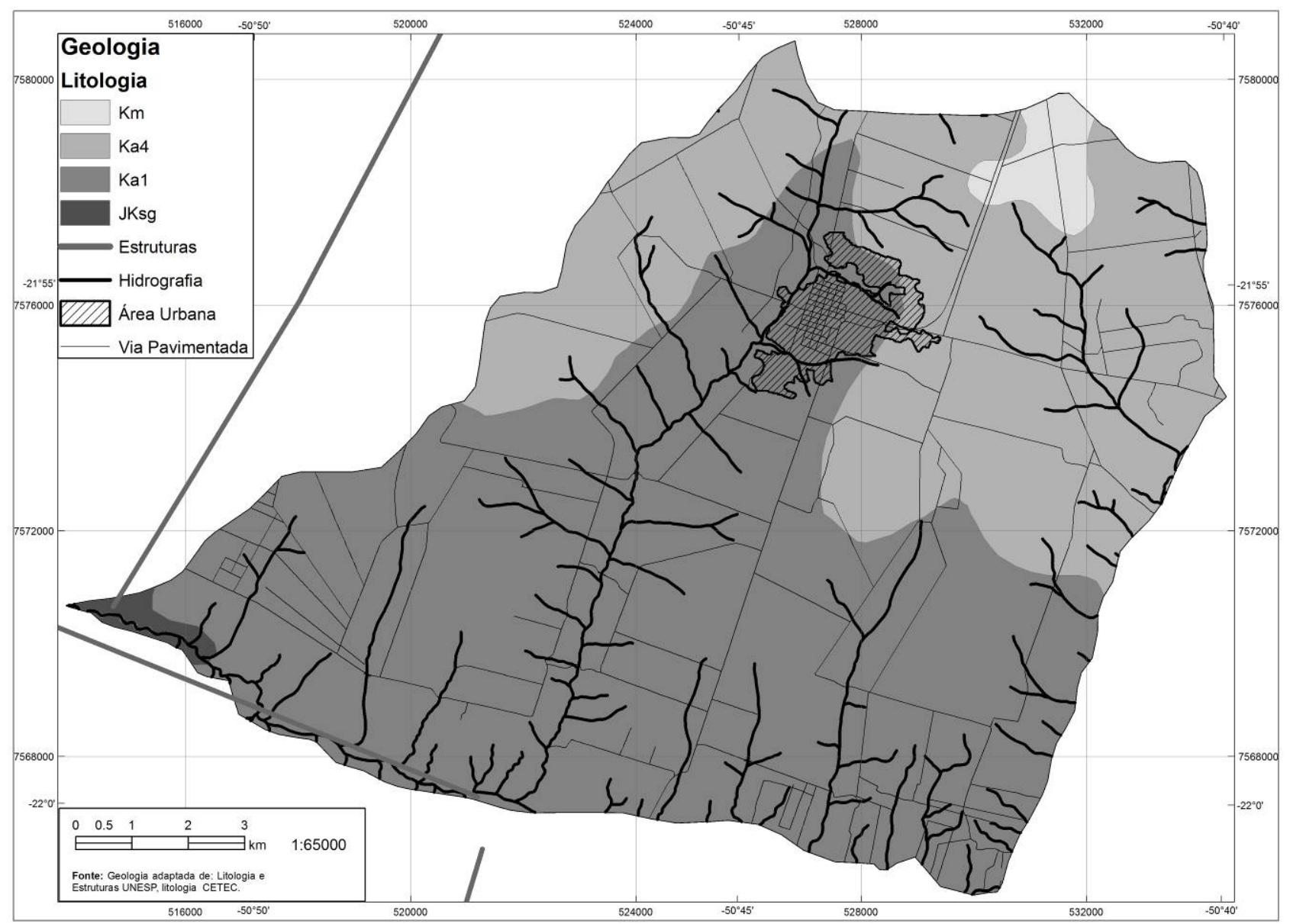

Figura 2 - Geologia da área estudo.

Na área de estudo aflora o Aquífero Adamantina, uma das unidades hidroestratigráficas do Sistema Aquífero Bauru subdivididas por Paula e Silva (2003). Segundo o autor, o Aquífero Adamantina é livre a semiconfinado, de extensão regional, e contínuo. Há predominância de sedimentos com permeabilidade aparente moderada. Segundo Mendonça e Gutierrez (2000), este aquífero tem caráter fortemente heterogêneo e anisotrópico, apresentando vazões variando de 5 a 50 m³/h, vazões específicas entre 0,5 e $3 \mathrm{~m}^{3} / \mathrm{h} / \mathrm{m}$ e transmissividades entre 10 e $100 \mathrm{~m}^{2} /$ dia.

Por ser um aqüífero livre, a recarga se faz em toda a sua extensão, o que aumenta o risco de poluição, a qual pode ser causada pelas atividades desenvolvidas sobre esta unidade hidrogeológica, chamando a atenção para a necessidade de um esforço conjunto do governo e da sociedade no desenvolvimento de programas e implantação de ações destinadas à sua proteção (IRITANI \& EZAKI, 2008).

\section{METODOLOGIA}


Após o levantamento bibliográfico as etapas de trabalho executadas foram as descritas a seguir.

\subsection{Levantamento Cartográfico}

Nesta etapa, efetuou-se o levantamento e obtenção de bases topográficas de escalas adequadas aos levantamentos (1:50.000) para a locação poços tubulares e para elaboração de mapas temáticos como o mapa potenciométrico.

\subsection{Levantamento Geofísico}

Com o intuito de melhor caracterizar a estratigrafia do Sistema Aquífero Bauru (SAB) na região foi efetuado um levantamento geofísico a partir da técnica da sondagem elétrica vertical (SEV), visando determinar a espessura do SAB, delimitar eventuais estratos e colher informações a respeito do seu embasamento (Sistema Aquífero Serra Geral). Foram executadas 03 três linhas com estaqueamento de 50 metros em área, e com dimensionamento de eletrodos suficientes para investigação em torno de 200 metros de profundidade, utilizando o arranjo gradiente multinível.

\subsection{Cadastro de Poços e Tratamento dos Dados Pré-existentes}

Um cadastro de poços tubulares foi feito a partir de consultas aos relatórios de perfuração de poços outorgados (SIDAS) no Departamento de Águas e Energia Elétrica de São Paulo (DAEE) sediado em Marília, reunindo-se informações sobre as características hidráulicas e construtivas dos poços, geologia e qualidade da água, dos quais incluem os registros históricos das concentrações de nitrato. Estes dados foram previamente tratados com o auxílio de métodos geoestatísticos e SIG. Essa atividade permitiu conhecer melhor a hidrogeologia da área de estudo e auxiliou a seleção dos poços mais representativos para amostragem e realização de análises físico-químicas e químicas em amostras de água subterrânea.

\subsection{Cadastro de Poços em Campo}

A partir da consolidação dos dados dos poços outorgados no DAEE, algumas propriedades foram selecionadas para cadastramento de poços em campo. O cadastro de poços permitiu reconhecer as condições sanitárias dos mesmos, bem como de seu entorno imediato, buscando-se a presença de fontes potenciais de poluição e potencial perigo de contaminação. 
As propriedades foram previamente selecionadas de acordo com os seguintes critérios:

- Diferentes atividades na propriedade, procurando abranger tanto granjas, sítios e outras atividades agropecuárias com base nos dados do CATI/LUPA (consulta, 2015);

- Presença de fontes potenciais de poluição cadastradas do banco de dados da SIPOL, da CETESB. Vale citar que poucas fontes potenciais do SIPOL foram identificadas, tendo em vista que o estudo é realizado na área rural;

- Propriedades com poços contendo diferentes concentrações de nitrato;

- Propriedades e poços previamente cadastrados e não cadastrados e;

- Maior distribuição possível dos poços em área, respeitando os limites da área rural do município.

As informações pertinentes aos mesmos foram organizadas e consolidadas em planilhas, mediante o programa Excel.

\subsection{Amostragem de Água Subterrânea}

Com o intuito de checar as análises químicas dos poços outorgados compiladas e obter melhor caracterização hidroquímica.

Após a pré-seleção dos poços, baseada nos critérios acima citados, a última etapa de seleção consistiu na obtenção de permissão dos proprietários, solicitada previamente pelo Sindicato Rural de Bastos e no caso dos sítios, através de telefonemas. No caso de não permissão da amostragem, os poços foram substituídos por outros, utilizando-se os mesmos critérios acima citados.

A primeira campanha de amostragem foi executada em agosto de 2015, sendo coletadas 33 amostras de 30 poços, sendo duas duplicatas e um branco de campo.

A amostragem foi executada diretamente na saída de água dos poços em funcionamento, com purga prévia para remoção de água estagnada, conforme os procedimentos descritos por BARCELONA et al. (1985).

Os parâmetros físico-químicos, tais como temperatura, $\mathrm{pH}$ e condutividade elétrica foram medidos in situ a partir de equipamentos portáteis. O mesmo se procedeu em relação às alcalinidades parcial e total. Tal parâmetro foi medido a partir de titulação com ácido sulfúrico (H2SO4) padronizado e indicadores de viragem de $\mathrm{pH}$ (misto e fenolftaleína).

As amostras para análises de cátions foram filtradas mediante o uso de membranas de de acetato celulose de $0,45 \mu \mathrm{m}$, seguida de preservação química com HNO3 $(\mathrm{pH}<2)$. Todas as amostras foram refrigeradas em temperaturas de $4^{\circ} \mathrm{C}$ até a entrada nos laboratórios.

As amostras foram analisadas para os seguintes parâmetros: 
- Ânions: as análises dos ânions sulfato, cloreto, nitrato, nitrito, fosfato e fluoreto pelo método EPA 300.0 - 300.1, amônio (cromatografia iônica), N total (combustão/quimiluminescência) e N org (por diferença) estão sendo realizadas no LEBAC (Laboratório de Estudos de Bacias UNESP);

- Cátions: as análises para sódio e potássio foram realizadas no LEBAC (Laboratório de Estudos de Bacias UNESP) por cromatografia iônica, enquanto o cálcio e magnésio pelo método SMEWW 3120B (2012), no mesmo laboratório.

\subsection{Tratamento dos Dados}

Os dados obtidos foram tratados estatisticamente e em ambiente SIG.

As informações digitais (foto aérea do município, mapa viário, hidrografia, uso e ocupação do solo, poços outorgados cadastrados, poços das propriedades rurais, principais culturas agropecuárias, áreas de pastagem, fontes com potencial de poluição, avícolas cadastradas e fotointerpretadas) foram compiladas, integradas e homogeneizadas em bases digitais, a partir do programa ArcGis da ESRI.

Os resultados das análises químicas efetuadas nas amostras coletadas foram submetidos a dois tipos de controle de qualidade: cálculo do balanço iônico e análises laboratoriais em amostras duplicatas.

O balanço iônico foi calculado para todas as amostras coletadas em campo, de modo a se rastrear o erro de análise em termos do limite permitido, adotado como $\pm 10 \%$. Com o intuito de se caracterizar quimicamente as águas subterrâneas e estabelecer uma evolução hidroquímica da área, utilizou-se o diagrama triangular de Piper a partir do programa Aquachem, versão 5.1, da Schlumberger Water Services.

Adicionalmente, realizou-se a análise estatística básica dos resultados químicos e físicoquímicos visando conhecer e separar diferentes tipos de água.

\section{RESULTADOS OBTIDOS}

\subsection{Levantamento Geofísico}

Os resultados da SEV 1 (Figura 3) demonstraram a presença de anomalia condutiva nos níveis mais rasos, com profundidade de até 30m em uma das seções, podendo ser atribuída à presença de contaminantes. O topo da Formação Serra Geral foi identificado a uma profundidade de aproximadamente $100 \mathrm{~m}$. A continuidade deste contato, no entanto, fica indefinida a partir do ponto que é interceptado por uma descontinuidade subvertical, que pode tanto refletir uma variação lateral 
no padrão de resistividade dos basaltos, como também estar associado a uma estrutura geológica (tipo falhamento) ocasionando um aprofundamento no topo do basalto.

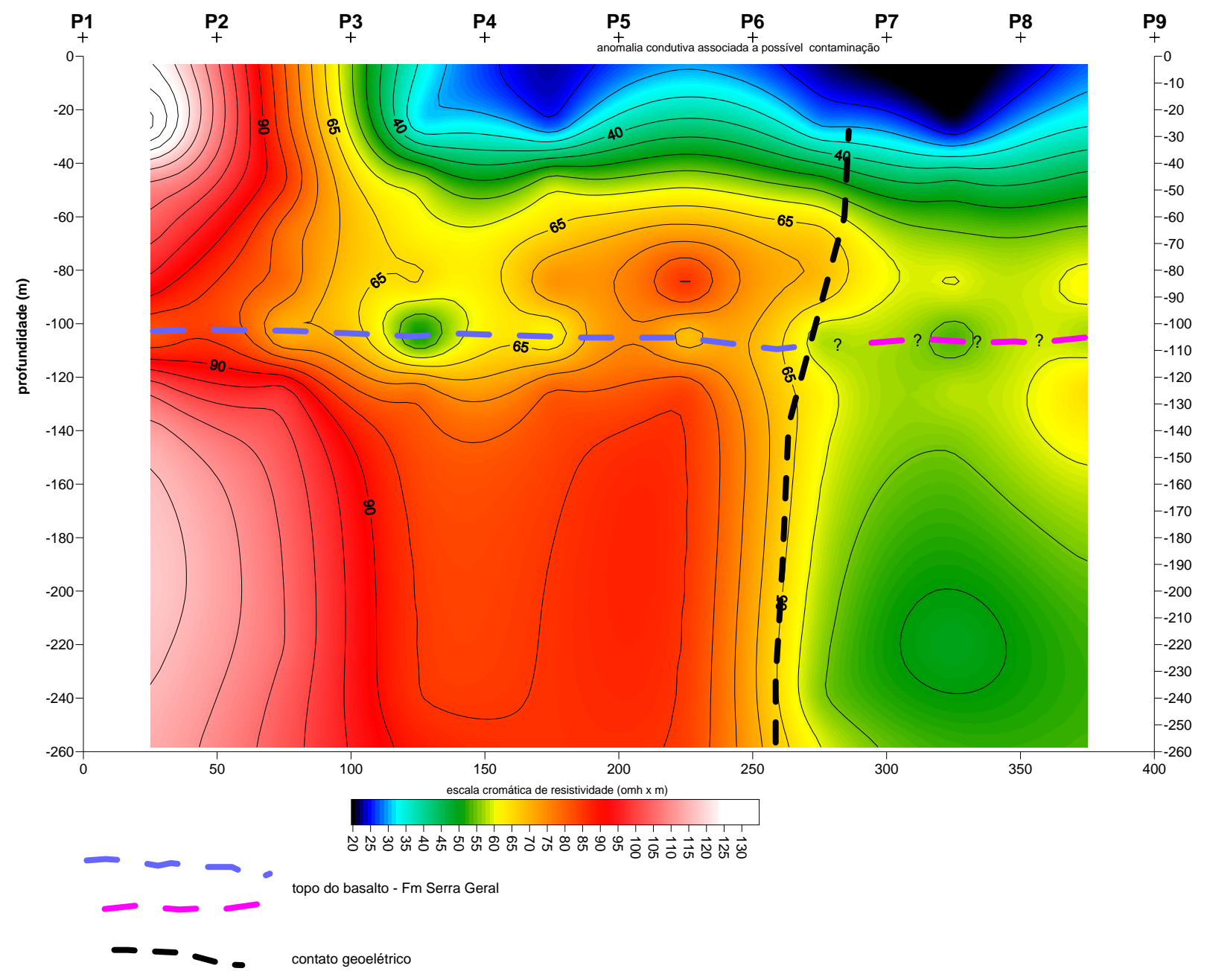

Figura 3 - Perfil da SEV 1.

Na SEV 2 (Figura 4) foi possível observar o contato geoelétrico sub-horizontal correlacionado ao topo dos basaltos da Formação Serra Geral entre 110 e 120m de profundidade. Não foi observada qualquer feição geoelétrica relacionada à presença de contaminação, apenas contrastes de resistividade na porção superior sedimentar, mostrando as variações faciológicas, ou seja, a intercalação de arenitos e siltitos.

Na terceira seção (SEV 3) também nota-se claramente o contato geoelétrico sub-horizontal relacionado ao topo da Formação Serra Geral, entre 120 e 130m; e presença de anomalia condutiva no domínio dos basaltos, podendo estar associada aos fraturamentos. Variações de resistividade na porção superior são devidas às variações no conteúdo areia/argila.

As localizações das 03 SEV’s podem ser visualizadas na Figura 6. 


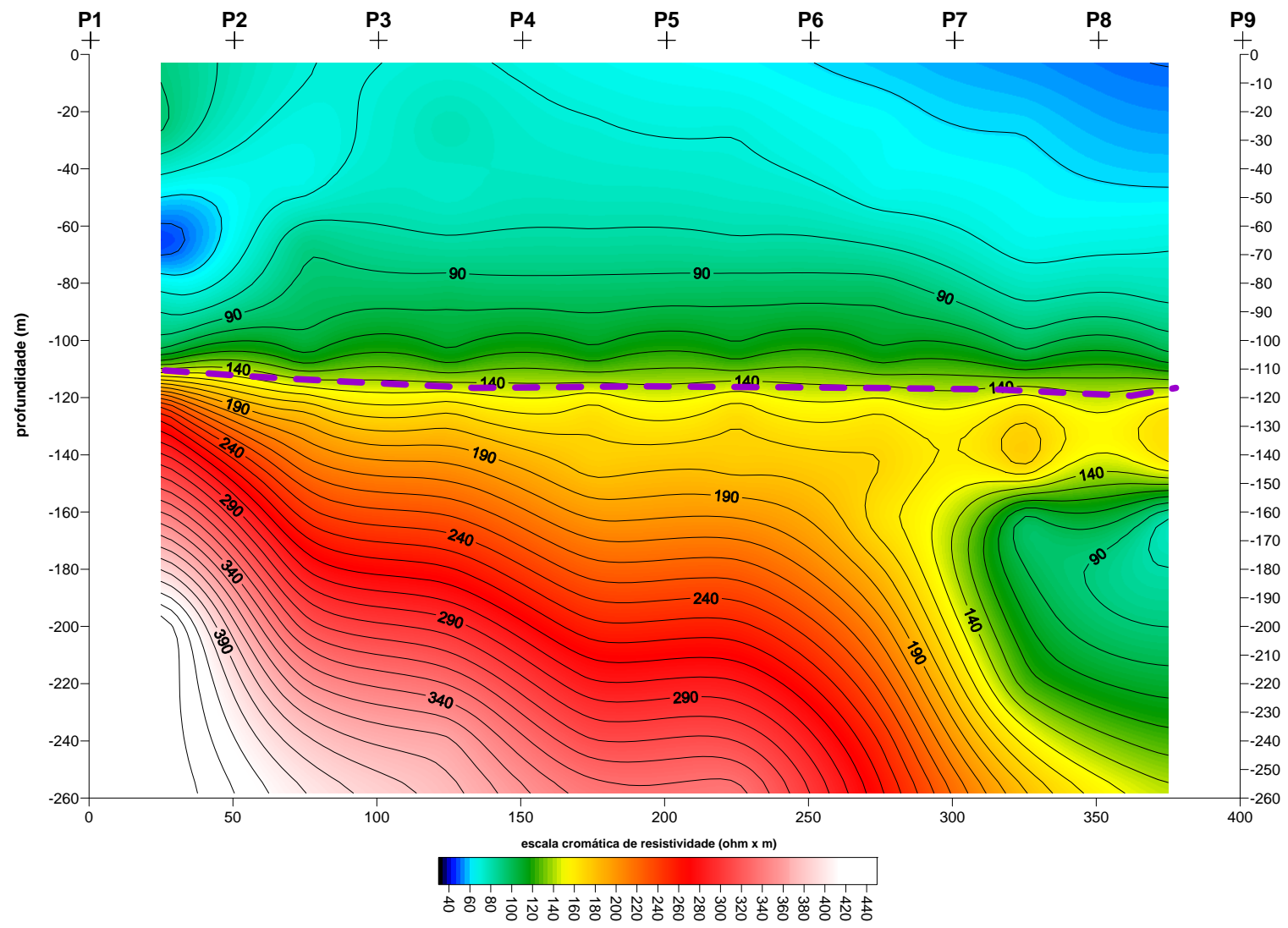

- - contato geoelétrico correlacionado ao topo do basalto - Fm Serra Geral

Figura 4 - Perfil da SEV 2.

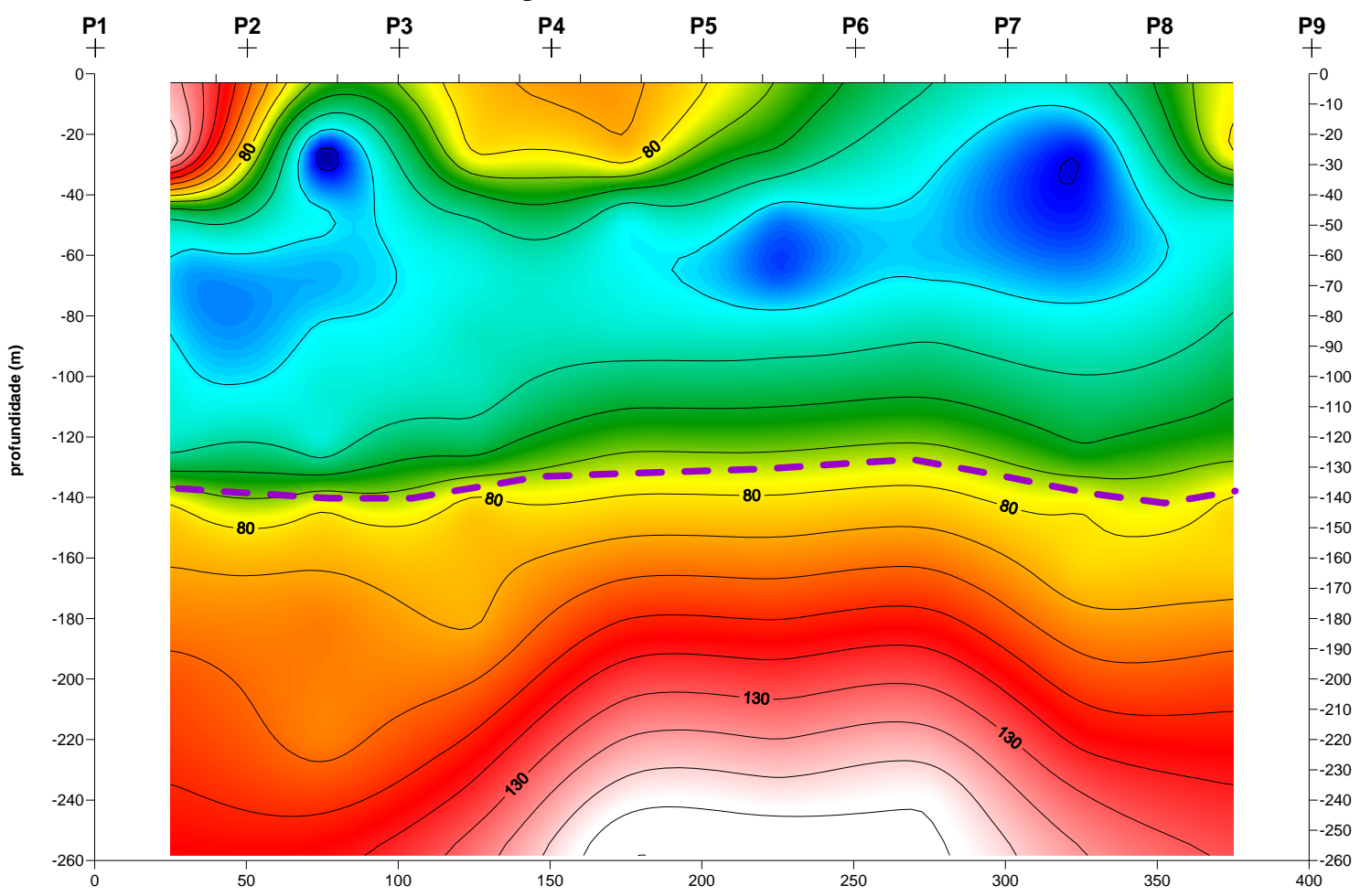

escala cromática de resistividade (omh $\mathrm{x}$ m)

Figura 5 - Perfil da SEV 3. 


\subsection{Compilação e Tratamento dos Dados de Poços Outorgados}

O cadastro final dos dados levantados diretamente nos processos de outorga do (DAEE) tem um total de 216 poços (Figura 6) de abastecimento públicos e privados, e foram sistematizados e compilados em uma planilha excel com as seguintes informações:

- proprietário: nome, contato, endereço;

- localização do poço: coordenadas UTM, cota, nome do local e bairro;

- dados construtivos: empresa e data de perfuração, profundidade, diâmetros de perfuração e profundidade dos filtros;

- parâmetros hidráulicos: nível estático, nível dinâmico, vazão, capacidade específica;

- perfil geológico e aquífero explorado;

- análises químicas efetuadas ao longo do tempo.

Adicionalmente, foram cadastrados em campo um total de 237 poços, distribuídos em 145 propriedades. Sendo 118 cadastrados apenas em campo, e 119 já cadastrados também pelos processos de outorga do DAEE (Figura 6).

\subsubsection{Geologia e Parâmetros Hidrogeológicos}

Dentre os poços cadastrados, poucos apresentaram descrição geológica detalhada. Como citado na revisão bibliográfica, os poços de abastecimento da região captam água dos aquíferos sedimentares Adamantina, do aquitarde Araçatuba e do aquífero fraturado Serra Geral.

Dentre as descrições obtidas para as respectivas formações geológicas, pode-se sintetizar:

Formação Adamantina: Arenito médio a grosso maciço, de cor avermelhada. Arenito fino a muito fino de coloração rosa a creme, com algumas intercalações de siltito e argilitos de coloração escura. Podendo ser maciço ou estratificado, com estratificação cruzada tabular e acanelada de pequeno porte. Em alguns poços foram identificadas além de lentes de siltito com espessuras variando entre 12 m e 22 m, algumas lentes de arenito conglomerático com intraclastos argilosos ou carbonáticos. Essas lentes foram também observadas principalmente nas SEV’s 2 e 3 .

Em dois poços foram observadas lentes com espessuras entre $12 \mathrm{~m}$ e $15 \mathrm{~m}$ de arenito carbonático, em profundidades mais rasas de até $30 \mathrm{~m}$.

Formação Araçatuba: localizado entre o Adamantina e o Serra Geral, constitui-se por lamito avermelhado; arenito muito argiloso, passando a argilito marrom escuro médio; siltito amarronzado, com níveis arenosos; e siltito cinza esverdeado. Ocorrem alguns níveis de arenito silificado creme a marrom, compacto. 


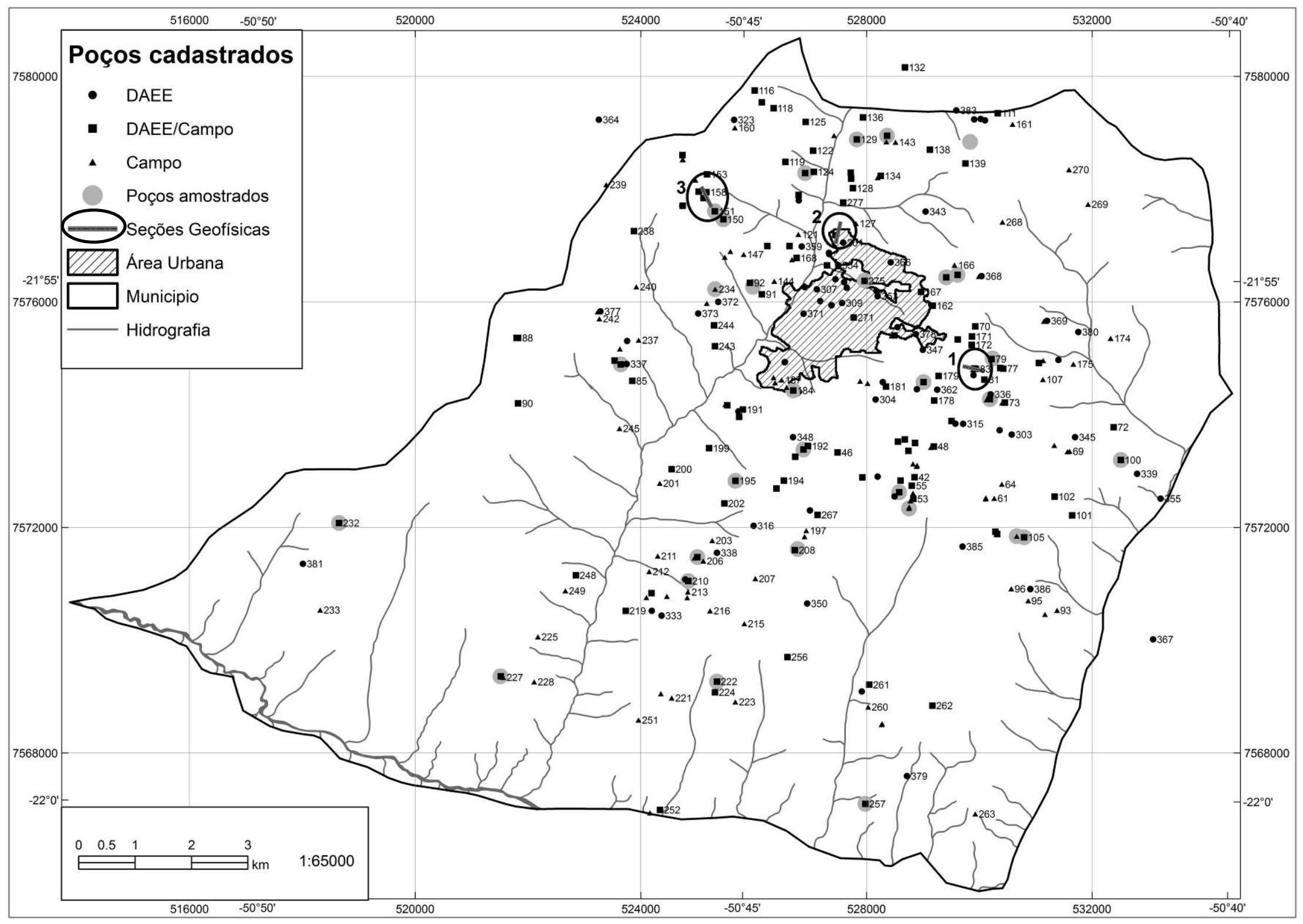

Figura 6 - Mapa de Atividades. 
Formação Serra Geral: a Formação Serra Geral é caracterizada por basalto marrom acastanhado a acinzentado, mole a semi-duro, e quando fraturado, apresenta alteração parcial e minerais secundários. Pode apresentar também vesículas/amigdalas preenchidas por calcita, olivina e epidoto.

Pôde-se observar que a Formação Adamantina aflora em média na cota 453 m, com cotas menores em direção aos vales (chegando a $381 \mathrm{~m}$ ) e espessuras variando entre 80 e $150 \mathrm{~m}$. Sobrepostos aos depósitos pelíticos da Formação Araçatuba, que aflora em cotas variadas (322 m $351 \mathrm{~m}$ ), dependendo do topo do basalto da Formação Serra Geral, sotoposto a ela. Sua cota média é de $336 \mathrm{~m}$ e ocorre com espessuras entre 13 e $34 \mathrm{~m}$. O topo do basalto ocorre a profundidades entre 95 e 150 m, confirmando o resultados observado nas SEV's. Os poços que captam água do Serra Geral possuem profundidades entre $240 \mathrm{~m}$ e $283 \mathrm{~m}$.

Quanto aos parâmetros hidrogeológicos, pode-se observar que os poços que têm filtro somente no Aquífero Adamantina possuem níveis estáticos (NE - média de 30 m) e dinâmicos (ND - média de $49 \mathrm{~m}$ ) mais rasos que os poços que também captam água do Serra Geral (NE - média de $121 \mathrm{~m}$ e ND - média de $147 \mathrm{~m})$, bem como menores vazões de exploração $\left(10 \mathrm{~m}^{3} / \mathrm{h}<46 \mathrm{~m}^{3} / \mathrm{h}\right)$ e vazões específicas $\left(2,3 \mathrm{~m}^{3} / \mathrm{h} / \mathrm{m}<16,5 \mathrm{~m}^{3} / \mathrm{h} / \mathrm{m}\right)$ médias.

\subsubsection{Potenciometria}

O fluxo da água subterrânea no Aquífero Adamantina que tem comportamento livre, segue em direção às drenagens principais, que atuam como áreas de descarga regional (Figura 7).

Apresenta superfície potenciométrica variando entre as cotas de $490 \mathrm{~m}$ a $350 \mathrm{~m}$. As cotas mais altas encontram-se na porção nordeste do município, onde afloram sedimentos do Aquífero Marília. E as mais baixas (350 m), encontram-se no limite sul do município, constituído pelo Rio do Peixe, uma das principais áreas de descarga regional, que possui uma grande extensão e faz divisa com o município de Rancharia. A outra área de descarga regional é o Ribeirão Copaíba, com carga hidráulica próxima a 370 m, localiza-se no limite leste de Bastos, divisa com o município de Tupã.

A superfície potenciométrica indica a existência de um divisor de águas com um eixo NE-SW na porção nordeste do município, a leste da área urbana, e outro localizado no limite oeste do município, também com eixo NE-SW. A Figura 7 ilustra o mapa potenciométrico do município de Bastos. 


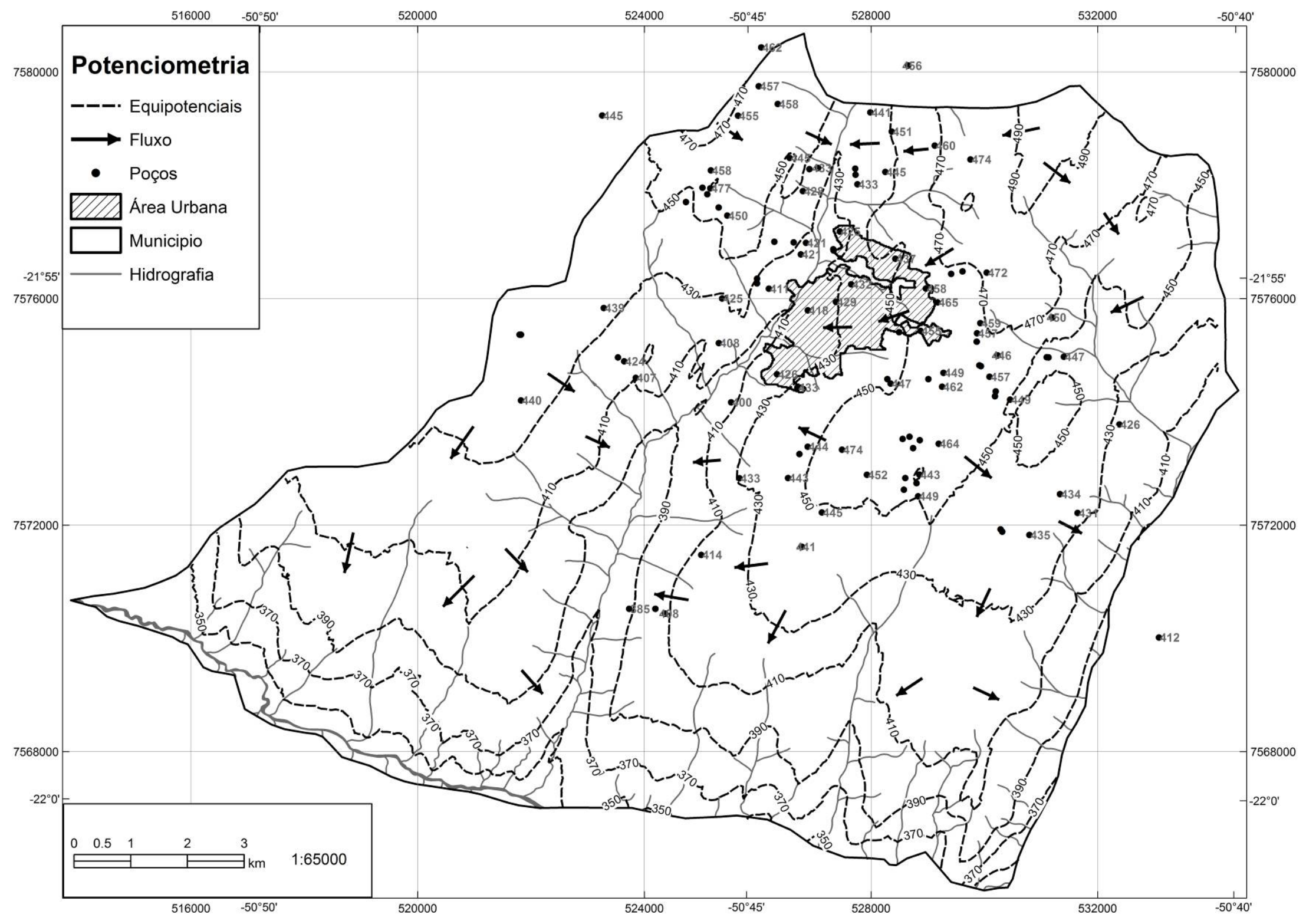

Figura 7 - Mapa Potenciométrico. 


\subsection{Hidroquímica dos Poços Amostrados}

\subsubsection{Classificação Hidroquímica}

Os resultados das análises químicas e físico-químicas das amostras de água dos poços que captam água somente do Adamantina indicam a ocorrência de água ácida, evidenciada pelos valores de pH entre 3,54 e 6,09. Já as águas dos poços que também captam água do Serra Geral apresentam pH’s mais alcalinos entre 6.94 e 9.01. O Eh é oxidante para todas as águas, variando entre $290 \mathrm{mV}$ e $717 \mathrm{mV}$, e média igual a $530 \mathrm{mV}$. A condutividade elétrica é variável, as mais baixas variando entre $16 \mu \mathrm{S} / \mathrm{cm}$ e $140 \mu \mathrm{S} / \mathrm{cm}$, com média de $216 \mu \mathrm{S} / \mathrm{cm}$ e máximas variando entre $649 \mu \mathrm{S} / \mathrm{cm}$ e $1010 \mu \mathrm{S} / \mathrm{cm}$.

A classificação das amostras de água subterrânea pelo Diagrama de Piper (Figura 8) para a campanha de amostragem mostra diferentes tipos hidroquímicos. Quanto aos ânions, existem águas predominantemente bicarbonatadas e águas nitratadas. Uma única amostra de poço que capta o Serra Geral apresentou maiores teores de sulfato. As águas bicarbonatadas tendem a ser predominantemente potássicas/sódicas e cálcicas em menor proporção, e as águas nitratadas tendem a ser magnesianas/cálcicas.

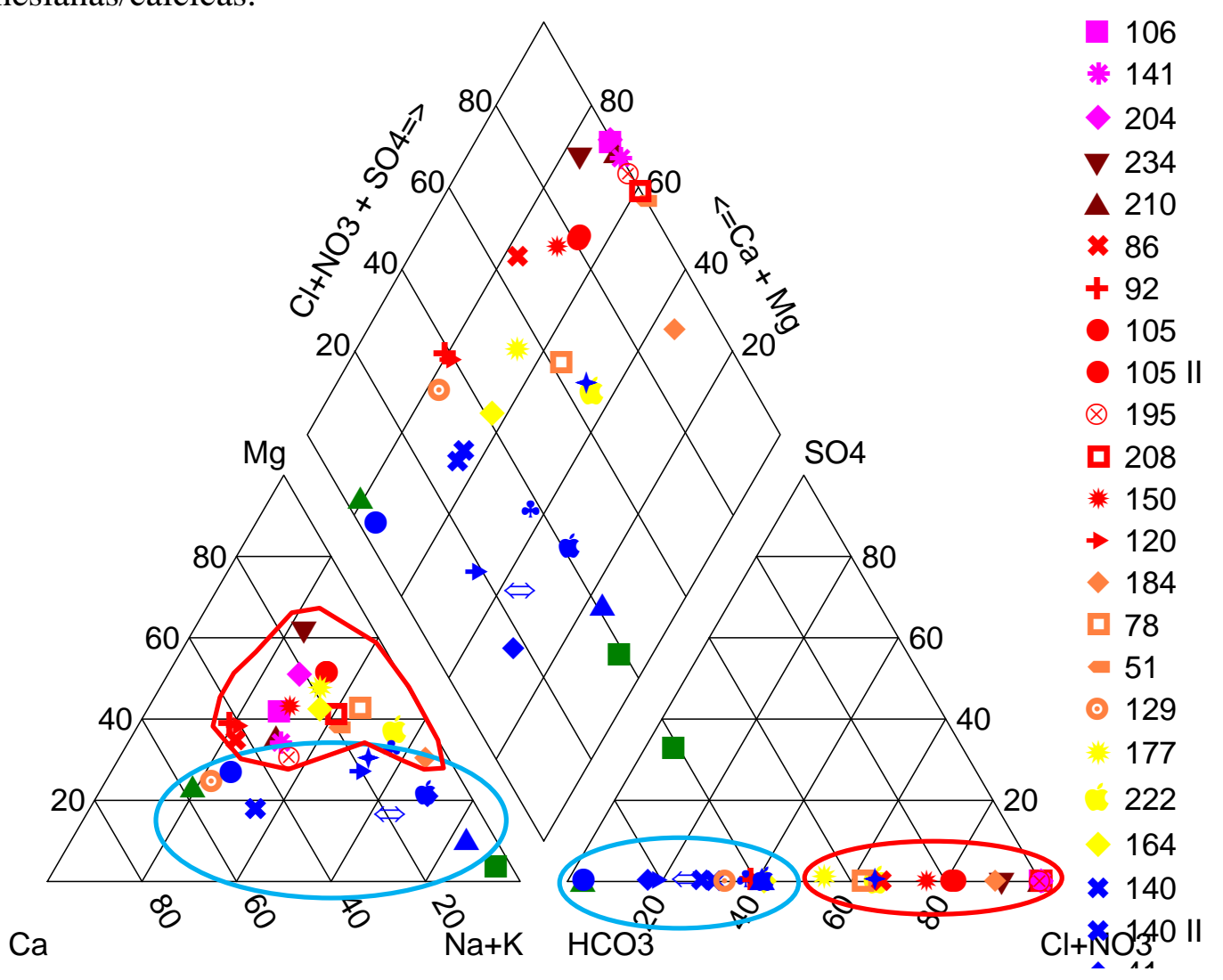

Figura 8 - Diagrama de Piper dos poços amostrados (agosto/2015). 
As águas nitratadas claramente apresentam alteração de qualidade por atividades antrópicas. Na Tabela 1 pode-se observar pH’s mais ácidos, maiores condutividades elétricas, teores de cloreto, nitrato, nitrito, nitrogênio total e cátions em geral.

Tabela 1 - Dados estatísticos para os dois principais tipos de água.

\begin{tabular}{|c|c|c|c|c|c|c|c|c|c|c|c|}
\hline \multicolumn{7}{|c|}{12 amostras bicarbonatadas sódicas potássicas } & \multicolumn{5}{|c|}{13 amostras nitratadas magnesianas cálcicas } \\
\hline & & Máximo & Mínimo & Média & Mediana & $\begin{array}{l}\text { Desvio } \\
\text { Padrão }\end{array}$ & Máximo & Mínimo & Média & Mediana & $\begin{array}{l}\text { Desvio } \\
\text { Padrão }\end{array}$ \\
\hline $\mathrm{pH}$ & & 9.01 & 4.20 & 5.23 & 4.61 & 1.44 & 5.65 & 3.54 & 4.56 & 4.43 & 0.66 \\
\hline Eh & $\mathrm{mV}$ & 702.20 & 290.20 & 491.58 & 486.65 & 119.76 & 668.40 & 408.10 & 541.02 & 561.20 & 68.70 \\
\hline CE & $\mu \mathrm{S} / \mathrm{cm}$ & 124.00 & 16.00 & 49.10 & 43.50 & 31.05 & 1010.00 & 173.00 & 396.08 & 276.00 & 248.29 \\
\hline $\mathrm{HCO} 3$ & $\mathrm{mg} / \mathrm{L}$ & 122.01 & 5.25 & 34.73 & 11.11 & 45.77 & 51.29 & 0.00 & 10.77 & 4.88 & 17.83 \\
\hline CO3 & $\mathrm{mg} / \mathrm{L}$ & 5.59 & 0.00 & 0.47 & 0.00 & 1.61 & 0.00 & 0.00 & 0.00 & 0.00 & 0.00 \\
\hline $\mathrm{Cl}$ & $\mathrm{mg} / \mathrm{L}$ & 5.18 & 0.62 & 1.96 & 1.80 & 1.36 & 28.60 & 3.31 & 10.38 & 8.08 & 7.22 \\
\hline SO4 & $\mathrm{mg} / \mathrm{L}$ & 46.60 & 0.03 & 3.95 & 0.04 & 13.43 & 0.28 & 0.01 & 0.04 & 0.01 & 0.09 \\
\hline$F$ & $\mathrm{mg} / \mathrm{L}$ & 0.25 & 0.02 & 0.06 & 0.03 & 0.08 & 1.00 & 0.01 & 0.25 & 0.10 & 0.29 \\
\hline PO4 & $\mathrm{mg} / \mathrm{L}$ & 2.61 & 0.01 & 0.29 & 0.05 & 0.73 & 0.14 & 0.01 & 0.04 & 0.02 & 0.04 \\
\hline N-NO3 & $\mathrm{mg} / \mathrm{L}$ & 3.93 & 0.19 & 1.96 & 2.25 & 1.31 & 105.00 & 16.62 & 36.76 & 23.94 & 26.81 \\
\hline N-NO2 & $\mathrm{mg} / \mathrm{L}$ & 0.01 & 0.01 & 0.01 & 0.01 & 0.00 & 0.01 & 0.01 & 0.01 & 0.01 & 0.00 \\
\hline $\mathrm{NH} 4$ & $\mathrm{mg} / \mathrm{L}$ & 0.07 & 0.03 & 0.03 & 0.03 & 0.01 & 0.17 & 0.03 & 0.04 & 0.03 & 0.04 \\
\hline $\mathrm{N}$ total & $\mathrm{mg} / \mathrm{L}$ & 3.57 & 0.17 & 1.77 & 2.05 & 1.19 & 89.17 & 14.82 & 33.59 & 20.52 & 23.89 \\
\hline DOC & $\mathrm{mg} / \mathrm{L}$ & 0.14 & 0.01 & 0.07 & 0.06 & 0.06 & 0.49 & 0.02 & 0.23 & 0.23 & 0.14 \\
\hline $\mathrm{Ca}$ & $\mathrm{mg} / \mathrm{L}$ & 21.50 & 0.30 & 4.38 & 1.50 & 6.27 & 36.40 & 4.11 & 15.25 & 17.80 & 9.27 \\
\hline $\mathrm{Mg}$ & $\mathrm{mg} / \mathrm{L}$ & 5.28 & 0.33 & 1.66 & 1.31 & 1.46 & 28.90 & 6.15 & 13.27 & 10.50 & 6.82 \\
\hline $\mathrm{K}$ & $\mathrm{mg} / \mathrm{L}$ & 5.71 & 1.02 & 3.67 & 3.58 & 1.21 & 37.00 & 7.82 & 16.29 & 12.00 & 9.11 \\
\hline $\mathrm{Na}$ & $\mathrm{mg} / \mathrm{L}$ & 73.80 & 0.85 & 8.82 & 2.78 & 20.51 & 17.80 & 3.98 & 7.39 & 6.33 & 4.01 \\
\hline Si & $\mathrm{mg} / \mathrm{L}$ & 21.70 & 12.50 & 15.18 & 14.20 & 2.97 & 16.60 & 10.80 & 13.12 & 12.90 & 1.85 \\
\hline
\end{tabular}

\section{CONCLUSÕES}

Na área de estudo, o Sistema Aquífero Bauru é representado pelo Aquífero Adamantina que possui cerca de 80 a $150 \mathrm{~m}$ de espessura, e pelo Aquitarde Araçatuba que ocorre sotoposto ao Aquífero Serra Geral com espessuras variando entre 13 e 34 m.

Sendo um aquífero livre na região, ou seja, não apresentando semi-confinamento pelo Aquífero Marília, o fluxo subterrâneo segue em direção às drenagens principais, constituídas pelo Rio do Peixe no limite sul do município, e pelo Ribeirão Copaíba, no limite leste do município. Existindo dois divisores de água, um na porção nordeste do município a leste da área urbana com eixo NE-SW e outro no limite oeste do município também com eixo NE-SW. 
O estudo da hidroquímica mostra diferenciação de dois tipos de água, um de composição bicarbonatada potássica sódica e por vezes cálcica, e outro de composição nitratada magnesiana cálcica, por vezes potássica. O primeiro tipo reflete a qualidade natural das águas do Adamantina na região e a segunda, apresenta claramente alteração de qualidade por fonte antrópica.

De acordo com os resultados aqui apresentados, é necessário um controle e fiscalização para evitar poços mal construídos e/ou mal conservados, que possam carrear a contaminação para unidades hidrogeológicas mais profundas e os novos poços construídos.

Dar-se-á continuidade aos estudos sobre a alteração da qualidade das águas no município de Bastos, com o objetivo de identificar quais as possíveis fontes associadas, de forma a se definir ações para mitigação do problema.

\section{AGRADECIMENTOS}

Os autores expressam seus agradecimentos ao FEHIDRO (Projeto “Estudos de Restrições em Aquíferos no Alto Aguapeí e Alto Peixe (Bauru e Guarani)”) pelo financiamento do projeto; ao DAEE, DAEM, Prefeitura Municial de Bastos e Sindicato Rural de Bastos pelo fornecimento de dados e apoio logístico; à Ana Paula de Jesus Rios pelo apoio em campo; aos técnicos de apoio de campo, bem como aos estagiários Márcio Fukamizo, Victor Martiliano de Oliveira e Marcela Denis Rissard, do IPT.

\section{REFERÊNCIAS BIBLIOGRÁFICAS}

BARCELONA, M.J.; GIBB, M.J.; HELFRICH, J.A.; GARSKE, E.E. 1985. Practical guide for groundwater sampling. Illinois State Water Survey, 94 p. (Contract Report, 374) URL: http://www.epa.gov/swerust1/cat/pracgw.pdf.

BASTOS, 2011. Avicultura. Disponível em <http://www.bastos.sp.gov.br/avicultura.php>. Acessado em 08 de agosto de 2013.

BASTOS, 2014. PREFEITURA MUNICIPAL DE BASTOS - PMB. Histórico do município. Disponível em: <www.bastos.sp.gov.br>. Acesso em: 05 Ago. 2014.

CATI - Coordenadoria de Assistência Técnica Integral, 2009. Projeto LUPA - Levantamento Censitário das Unidades de Produção Agropecuária do Estado de São Paulo. CATI / SAA, 2009.

DAEE - DEPARTAMENTO DE ÁGUAS E ENERGIA ELÉTRICA, 1979. Estudo de águas subterrâneas, regiões administrativas 10 e 11: Presidente Prudente e Marília. São Paulo - SP: v.1 e v.2. 
DAEE/UNESP (Convênio). 1984. Mapa Geológico do Estado de São Paulo- Folhas de Dracena e Araçatuba, escala 1:250.000.

DAEE - DEPARTAMENTO DE ÁGUAS E ENERGIA ELÉTRICA. 2005. Síntese dos Planos de Bacia - Plano Estadual de Recursos Hídricos São Paulo: DAEE/Consórcio JMRENGECORPS (Relatório $n^{\circ}$ 1/2005).

ENGFLORA Engenharia e Meio Ambiente, 2014. Plano Municipal de Gestão Integrada de Resíduos Sólidos. Relatório Preliminar. Etapa 01 e 02 - Versão para Audiência Pública. Bastos, Outubro de 2014.

CENTRO TECNOLÓGICO DA FUNDAÇÃO PAULISTA - CETEC. Relatório de Situação dos Recursos Hídricos das Bacias dos Rios Aguapeí - Peixe - Relatório zero. 1997. COMITÊ DAS BACIAS HIDROGRÁFICAS DOS RIOS AGUAPEÍ PEIXE - CBH-AP.

FREITAS, J. L. M. 2015. Avaliação preliminar da contaminação do aquífero Bauru em um município com vocação para avicultura. Dissertação (Mestrado) - Faculdade de Engenharia, Universidade Estadual Paulista, Bauru, 68p.

IRITANI, M. A.; EZAKI, S. 2012. As águas subterrâneas do Estado de São Paulo. São Paulo : Secretaria de Estado do Meio Ambiente - SMA, 2012.

MENDONÇA, J.L.G.; GUTIERREZ, T.M.C. 2000. O Potencial Hidrogeológico no Estado de São Paulo. I Congresso Internacional de Água Subterrânea. Fortaleza - Brasil. CD ROM.

PAULA e SILVA, F. 2003. Geologia de subsuperfície e hidroestratigrafia do Grupo Bauru no Estado de São Paulo. Tese de Doutorado. Instituto de Geociências e Ciências Exatas, Universidade Estadual Paulista. Rio Claro. 166 p.

ROCHA, G.A., GIANCURSI, F.D., PERRONI, J.C.A, SOBREIRO NETO, A.F., BERTACHINI, A.C., CORREA, W.A.G., CAMPOS, H.C.N.S., DIOGO, A., ROSA, R.B.G.S. \& CASTRO, C.G.J. 1979. Hidrogeologia das bacias dos rios Aguapeí, Peixe e Paranapanema no Estado de São Paulo. In: Simpósio Regional de Geologia, 2., Rio Claro. Atas...Rio Claro: SBG, 1979, v.2, p. 85-100.

SEADE - Fundação Sistema Estadual de Análise de Dados. Perfil municipal de Bastos. Disponível em <http://www.seade.gov.br/produtos/chartserver/imp/fc/lva/58/55,58,59/2010/00/1/2/>. Acessado em 07 de agosto de 2013. 
SOARES, P. C.; LANDIM, P. M. B.; FÚLFARO, V. J.; \& SOBREIRO NETO, A. F. 1980. Ensaio de caracterização estratigráfica do Cretáceo no Estado de São Paulo: Grupo Bauru. Revista Brasileira de Geociências, v. 3, n. 10, pp. 177-185.

VARNIER, C.L. 2011. Plano de Ação - Enfrentamento da Contaminação por Nitrato nas Águas Subterrâneas do Sistema Aquífero Bauru, Estado de São Paulo. In: INSTITUTO GEOLÓGICO. 2011. Projeto Ambiental Estratégico Aquiferos: síntese das atividades, período 2007-2010. IRITANI, M. A.; FERREIRA, L. M. R.; FERNANDES, A. J.; EZAKI, S. (ORG.). Instituto Geológico, São Paulo, p. 99-101. 